\title{
Surya namaskar: a way to relax the mind
}

\begin{abstract}
Surya namaskar is a practice which has been handed down from the sages of Vedic times and is an integral part of yogic approach. Surya means 'sun' and namaskar means 'salutation'. So, Surya namaskar means 'salutation to sun. It can be easily integrated into our daily lives as it require only five to fifteen minutes of practice daily to obtain beneficial results. It is a branch of yoga that concentrates on physical health and mental well-being. Through practicing various body postures (asana), breathing techniques (pranayama), and meditation, it is believed that one can obtain a calm and peaceful mind
\end{abstract}

Keywords: surya namaskar, asanas, peaceful mind, lustrous gem, manipura chakra
Volume I Issue 6 - 2017

\author{
Priyanka Malhotra \\ Institute of Mental Health, University of Health Science, India
}

Correspondence: Priyanka Malhotra, MSc in Psychiatry Nursing, Institute of Mental Health, Pt. Bhagwat Dayal Sharma, University of Health Science, Rohtak- I2400I, Haryana, India, Email priyanka.malhotra23@yahoo.com.au

Received: December II, 2017 | Published: December 29, 2017
Abbrevations: RAM, roy's adaptation model; STAXI, state trait anger expression inventory

\section{Introduction}

In our body there is a Manipura Chakra, located in the area of the solar plexus, navel, and the digestive system, also called as "lustrous gem". This chakra associated with the colour yellow and involved in self-esteem, energy, power of transformation; it also governs digestion and metabolism. A healthy, spirited third chakra supports in overcoming inertia, get-up-and-go attitude so that persons can take risks, assert their will, and assume responsibility for the life. This chakra is also the place of deep belly laughter, warmth, ease, and the vitality that receive from performing selfless service. ${ }^{1}$ Digestive problems, eating disorders, feeling like a victim, or experiencing low self-esteem are the indications of a deficient third chakra. Perfectionism, anger, hatred, and too much emphasis on power, status and recognition reveal an excessive third chakra. People are living in a time where there is little encouragement for paying attention to body's natural energy levels and giving it what it needs. ${ }^{2}$ So often when they are really tired, they ignore body need for rest and manipulate body need with caffeine, sugar, and other stimulants to create a false sense of energy. When they over stimulated and want to relax or draw inward, they turn to overeating, alcohol, or drugs to slow down. Yoga offers a different choice to listen to what the body requires and to truly nourish itself, using appropriate asanas and pranayama practices to create more energy or relaxation. ${ }^{3}$

Surya namaskar is an ideal way to relax the mind as it uses the whole body and produces sweating. This can lead to great burn off anger and allow to calmly dealing the situation with full of awareness. ${ }^{4,5}$ Studies have documented the effect of Surya namaskar on direct vitalizing of the energy in the body namely pingala nadi and a regular practice of Surya namaskar helps in regulation of pingala leads to a balanced energy system at both mental and physical levels. ${ }^{6-8}$

\section{Materials and methods}

The present study was conducted in a tertiary care centre of the North India. Purposive sample technique was used to collect the sample and 60 male adults with substance use disorders were used in the study. For the assessment of peaceful mind STAXI-(State Trait
Anger Expression Inventory) was used., ${ }^{910}$ A conceptual framework based on Roy's Adaptation Model was formulated and applied on the present study.

The Roy's Adaptation Model (RAM) is an effective frame work for addressing the adaptive needs of individual, family and groups. The core of Roy's adaptation model is the belief that a person's adaptive responses are a function of the incoming stimulus and the adaptive level. ${ }^{11-16}$

The following are the main components of the adaptation system and are represented in (Figure 1).

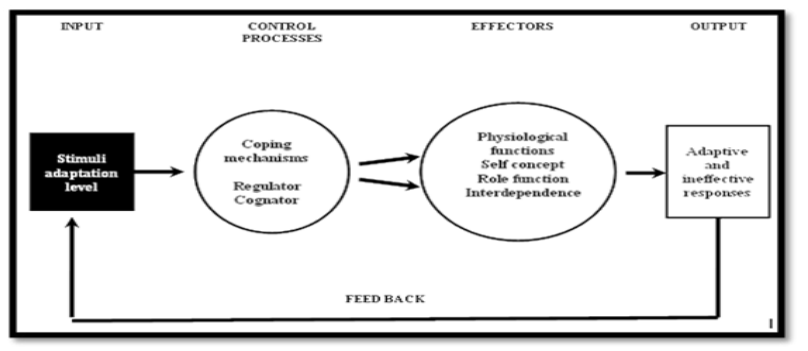

Figure I Roy's adaptation model.

\section{Application of Roy's adaptation model as conceptual framework in the present study}

According to Roy's Adaptation model nursing goals were achieved by assessing the behaviour and other factors that influence adaptive abilities of study subjects. This principle is being conceptualized in the assessment phase of present study in the anger management. In the first level of behavioural assessment, the output behaviours of the person were gathered in relation to the four adaptive modes of the adaptive system. This has been achieved by screening with (STAXI). The results were identified under the four adaptive modes in terms of the following ways (Figure 2).

Physiological physical mode: Restlessness due to yelling at somebody, shouting out loud, loses temper.

Self -concept: Guilt feelings disturbed self image due to poor insight and getting angry.

Role function: Difficulty in performing routine activities. 
Interdependence: Arguments, interpersonal conflicts related to intoxication disturbed.

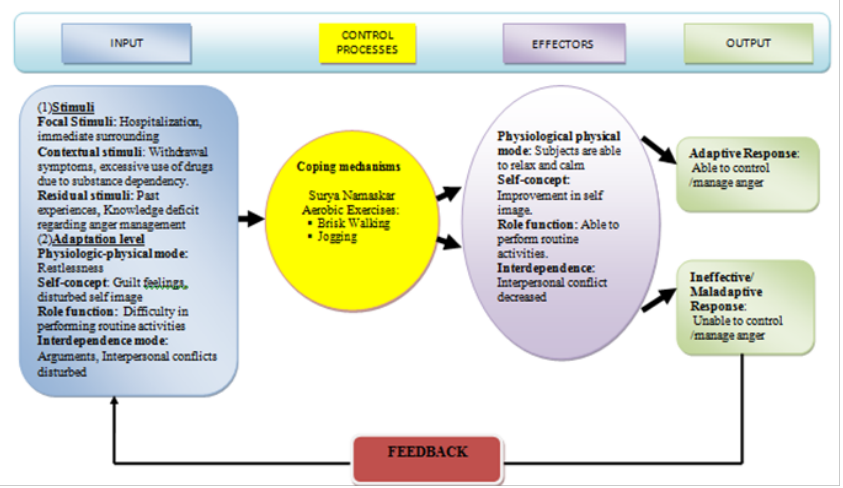

Figure 2 Conceptual framework based on Roy's adaptation model (RAM).

The second level assessment clarifies the significant factors impacting on the client for relaxing the mind. The occurrence of any stimuli that influences the adaptive modes of the person was identified in terms of the following ways.

Focal stimuli is the stimulus most immediately confronting the person and the one to which the person must make an adaptive response. In the present study the focal stimuli were; hospitalization and immediate surroundings.

Contextual stimuli are all the other stimuli that contribute to the behaviour caused or precipitated by the focal stimuli. In the present study the contextual stimuli were; hereditary and constitutional factors, physical and emotional problems like withdrawal symptoms, excessive use of drugs that are present due to substance dependency.

Residual Stimuli are those that are difficult to measure objectively. In the present study residual stimuli were; past experiences related to hospitalization, knowledge deficit regarding relaxing the mind.

Control Process: Control process refers to the coping mechanisms of the person. In order to relax the mind substance dependence subjects were using alcohol and other dependent substance as a coping mechanism. Researcher implemented Surya namaskar as a way of coping mechanism in order to relax the mind.

Effectors: Effectors are the four adaptive modes that are changed due to change in control processes (coping mechanism). Effectors that were changed due to Surya namaskar are:

Physiological physical mode: subjects are able to relax and calm.

Self-concept: improvement in self image.

Role function: able to perform routine activities.

Interdependence: Interpersonal conflict decreased.

Output: Output was categorized as adaptive or maladaptive/ineffective responses. Subjects verbalized either adaptive or ineffective response depending on the ability to relax the mind. The feedback evaluated with the help of State-Trait Anger Expression Inventory- (STAXI-) after fifteen days of intervention in experimental group and in control group without intervention feedback was evaluated with the help of STAXI- after fifteen days.

\section{Results and discussion}

As per State-Trait Anger Expression Inventory- study subjects were distributed according to percentile of anger scores. Scores between the $25^{\text {th }}$ and $75^{\text {th }}$ percentiles were considered to fall in the normal range. Individual with anger scores above the $75^{\text {th }}$ percentile experiences and /or express angry feelings to a degree that may interfere with optimal functioning and dispose them to develop psychological disorders. Score below the $25^{\text {th }}$ percentile indicates use of denial and repression for coping with and avoiding anger. As no subject fell in the score range below $25^{\text {th }}$ percentile, so all the subjects were distributed under high and normal anger range.

\section{Distribution of study subjects according to percentile of state anger scores as per STAXI}

Figure 3 shows the distribution of study subjects' state anger percentile scores according to STAXI- in pre and post interventional phase. Subjects were having high state anger during pre interventional phase i.e.33.3\% and $40 \%$ in experimental group and control group respectively. After intervention all the subjects (100\%) in experimental group as well as in control group were fell in normal range. The difference in the pre and post test percentile of state anger scoring in the control group could be attributed to the fact that control group was also not completely deprived of any intervention. Though not on physical exercises, yet verbal motivation, drugs to control addiction and other forms of treatment like psychotherapy have brought about significant differences within the control group.

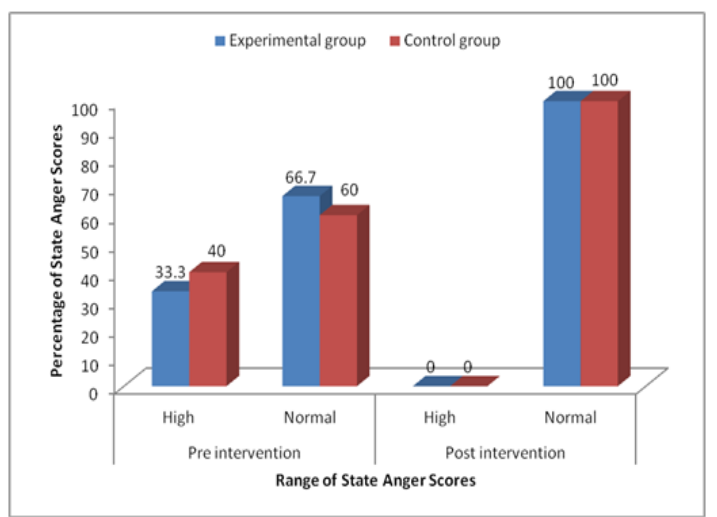

Figure 3 Distribution of study subjects according to percentile of State anger scores as per STAXI-2TM.

\section{Distribution of study subjects according to percentile of Trait anger scores as per STAXI}

Figure 4 shows the distribution of study subjects' trait anger percentile scores according to STAXI- in pre and post interventional phase. Maximum subjects were having high trait anger during pre test i.e. $100 \%$ and $93.3 \%$ in experimental group and control group respectively. During post assessment phase in the experimental group percentage of subjects having high trait anger reduced from $100 \%$ to 0 and all the subjects shifted to the range of normal trait anger and in the control group no change in the percentile of trait anger scores i.e. $93.3 \%$ in high trait anger. It shows that reduction in the trait anger scoring during post assessment phase was greater in experimental group as compare to the control group. 


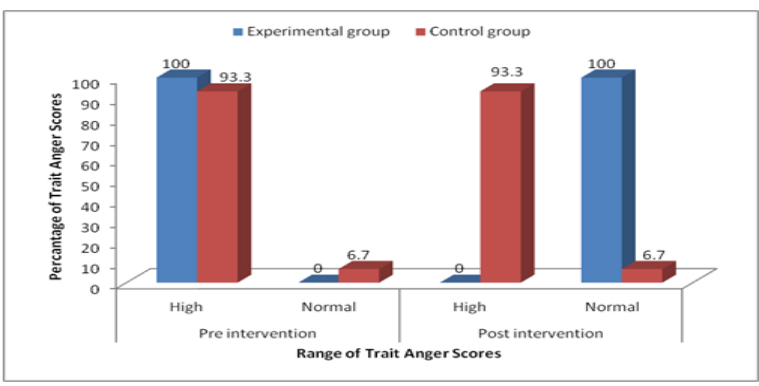

Figure 4 Distribution of study subjects according to percentile of Trait anger scores as per STAXI-2TM.

\section{Distribution of study subjects according to percentile of Anger Expression Index scores as per STAXI}

Figure 5 shows the distribution of study subjects' anger expression index percentile scores according to STAXI- in pre and post interventional phase. Maximum subjects were having high anger expression index during pre assessment phase i.e.100\% and $90 \%$ in experimental group and control group respectively. During post assessment phase in the experimental group percentage of subjects having high range of anger expression index reduced from $100 \%$ to 0 and all the subjects shifted to the range of normal anger expression index and in the control group percentage of subjects having high anger expression index reduced from $90 \%$ to $60 \%$. It shows that reduction in the anger scoring during post assessment phase was greater in experimental group as compare to the control group.

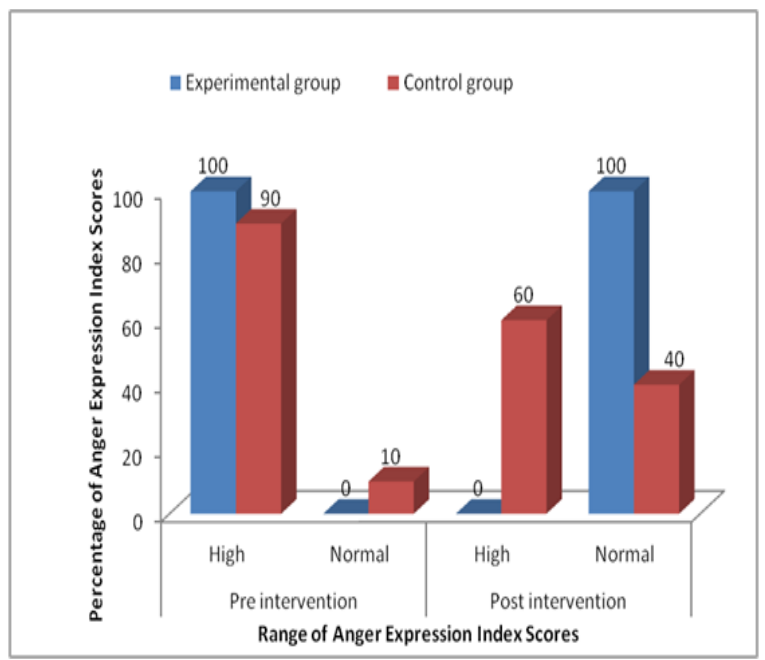

Figure 5 Distribution of study subjects according to percentile of Anger Expression Index scores as per STAXI-2TM.

\section{Conclusion}

The present study found that Surya Namaskar is the time saving, cost effective, priceless, non-pharmacological and effective way to relax the mind. However, more such studies can be conducted on large samles, different setting and for longer duration to support the results.

\section{Acknowledgements}

None.

\section{Conflicts of interest}

The authors declared that there are no conflicts of interest.

\section{References}

1. Sparrowe L. Yoga. 2nd ed. A Yoga Journal Book. Westport, USA: Hugh Lauter Levin; 2004.

2. Saraswati S. Asana, pranayama, mudra. 4th ed. Bihar, India: Yoga Publication Trust; 1999.

3. Stec K. Dynamic Suryanamaskar: Sun Salutation. 2nd ed. Bangalore, India: Swami Vivekananda Yoga Prakashana Publications (SVYP); 2012.

4. Saraswati S. Surya Namaskar: A Technique of Solar Vitalization. 2nd ed. Bihar, India: Yoga Publication Trust; 2007.

5. TNN. Benefits of surya namaskar. India: The Times of India; 2012.

6. Anand M, Alagesan J, Prathap S. Effect of yoga therapy in rehabilitation of drug addicts. Global Journal for Research Analysis. 2013;2(7):153-154.

7. Senthil Kumar V, Ganesh M, Duraisami V, et al. The effect of suryanamaskar and mantra chanting on anger among stressed men. Journal of Medical Science \& Technology. 2013;2(3):146-149.

8. Gupta A, Malik A. Sudarshan Kriya Yoga (SKY) as an adjunctive treatment in mental disorders: the magic unfolds. Dysphrenia. 2014;5(1):56-61.

9. Spielberger CD, Reheiser EC, Sydeman SJ. Measuring the experience, expression, and control of anger. Issues Compr Pediatr Nurs. 1995;18(3):207-232.

10. Spielberger CD. Professional manual for the State-Trait Anger Expression Inventory-2 (STAXI-2). Odessa, Florida, USA: Psychological Assessment Resources; 1999.

11. George BJ. Nursing theories-The base for nursing practice. 6th ed. New Delhi, India: Pearson Publication; 2011. p. 291-317.

12. Parker EM. Nursing theories and nursing practice. 2nd ed. New Delhi, India: Jaypee brother's medical publishers; 2007. p. 269-279.

13. Tomey AM, Alligwood MR. Nursing theorists and their works. 5th ed. Missouri, USA: Mosby; 2002. p. 266-298.

14. McCrady BS, Epstein EE. Addictions: A comprehensive guidebook. 1st ed. New York, USA: Oxford University Press; 1999.

15. Kleber HD, Weiss RD, Anton RF Jr, et al. Treatment of patients with substance use disorders. Am J Psychiatry. 2007;164(4 Suppl):5-123.

16. Lezak, MD, Howieson DB, Loring DW. The neuropsychological examination: Interpretation. 4th ed. New York, USA: Oxford University Press; 2004 